\title{
Paradigmas do envelhecer e cinema nacional: imagens da velhice construídas em Copacabana e Chega de Saudade ${ }^{1}$
}

\author{
Juliane Domingos Yamanaka²
}

\section{Resumo}

O fascínio por filmes que me acompanha já há algum tempo despertou a necessidade de olhá-los de forma mais aprofundada. Considerando os filmes um artefato cultural, o que num primeiro momento parecia ser apenas imagens em movimento tornou-se um objeto que poderia trazer interpretações possíveis diante de nossa cultura. Com isso, de forma mais contundente senti o anseio de investigar questões que viesse a surgir de filmes.

As imagens, de uma forma geral, atraem olhares atentos e desatentos que podem levar a caminhos muitas vezes não decifrados. Desse modo, pensar na imagem do idoso de hoje instigou meu interesse de buscar compreender pessoas inseridas nesse grupo, que, por mais que estivessem próximas de nós não deixam de ser o outro que a antropologia tanto nos remeteu com afinco. Assim, tornou-se necessário nesse meu percurso investigativo estudar o tema velhice e algumas de suas questões.

$\mathrm{O}$ envelhecimento passou a ser considerada uma questão social principalmente quando estudiosos dessa área, os gerontólogos, alertaram

\footnotetext{
${ }^{1}$ Essa pesquisa, de Iniciação Científica, foi financiada pela FAPESP de julho de 2011 até junho de 2012. Também foi apresentada como Monografia para obtenção do título de Bacharel/Licenciado em Ciências Sociais na Unifesp Guarulhos EFLCH, no ano de 2012.

2 Aluna de Pós-Graduação em Ciências Sociais/ Unifesp - Guarulhos. Orientadora: Andréa Barbosa. E-mail: julianedomyngos@gmail.com
} 
para os muitos problemas dessa camada populacional. Na contemporaneidade despertou na sociedade e principalmente no idoso a necessidade de afastar a degradação corporal. Para tanto, atividades físicas e procedimentos estéticos, para aqueles que se encontram na terceira idade, são paulatinamente apresentadas e inseridas em procedimentos considerados necessários para pessoas enquadradas nessa categoria etária.

Desse modo, essa pesquisa pretendeu averiguar imagens, porém aquelas que o cinema transmite em dois filmes nacionais que são: Copacabana (2001) e Chega de Saudade (2008). Os filmes destacados dialogam com essa parcela de nossa sociedade em que há personagens representantes da categoria social conhecida por suas derivadas classificações como: terceira idade, melhor idade, idosos, velhos.

No filme Copacabana a morte é utilizada como pano de fundo que envolve toda a trama. Contudo, a morte não é consequência para o angustiado protagonista que se sente encurralado ao completar 90 anos de vida e estar mais próximo da morte. Em Chega de Saudade a sociabilidade e a sexualidade dialogam o tempo todo, pois o filme trata de um baile de dança de salão onde se constroem e se realizam muitas relações, ora efêmeras, ora duradouras.

Vale ressaltar que a imagem do idoso de hoje mostra-se muitas vezes conflitante com a que foi no passado, mas também com o presente, aspecto este relacionado principalmente com a perda do vigor físico. Com a reorganização das normas vigentes estabelecidas aos idosos, em que estes passam a virar escravos do hoje esperando que o amanhã não chegue ou se atrase torna-se figura chave para o desenvolvimento de um mercado 
consumidor voltado ao ramo de cosméticos demonstrando preocupação com a imagem ${ }^{3}$.

Além disso, temas como sociabilidade, sexualidade e a morte são abordados de muitas maneiras, pois são construções sociais, que por estar em processo constante de transformação, são notadas e diferenciadas em cada momento determinado, em que a longevidade humana passa a ser um dos princípios norteadores dessa situação.

Relacionando o contexto ao texto, os filmes apresentam os três temas já citados que considerei extremamente relevantes quando tratamos de elucidar a terceira idade e suas conquistas. Com isso, os longas metragens escolhidos para evidenciar tais aspectos trazem elementos que abrem espaços para falar sobre o envelhecimento assim como sobre a própria imagem da velhice e seus desdobramentos haja que o que vemos é sempre uma realidade reinventada nas telas.

Nesse sentido, pontos como a relação cinema e imaginário social e a possibilidade de diálogos entre essas duas instâncias merecem ser frisados, pois os filmes podem reconstruir uma dada realidade de determinados grupos na vida social, como também questioná-la.

Analisei, assim, os filmes e algumas de suas questões, de modo a percebê-los como forte presença na nossa convivência cotidiana multifacetada. Como formas de interpretação da realidade social, na qual estamos inseridos, as imagens do cinema são por muitas vezes apropriadas em nossas significações cotidianas da vida.

\footnotetext{
${ }^{3}$ Ver: DEBERT, Guita Grin. A Reinvenção da velhice: Socialização e Processos de Reprivatização do Envelhecimento. Editora da Universidade de São Paulo. Fapesp. São Paulo, 2004.
} 
Assim, as imagens na antropologia vêm historicamente sendo atribuídas de maneira variadas nos estudos científicos. "A câmera era considerada quase um instrumento de precisão, mas aos poucos o recurso da imagem na pesquisa antropológica foi se descolando da função de registro de dados etnográficos e ganhou outras possibilidades" (BARBOSA; CUNHA, 2006, p. 49). Deste modo, se pensarmos nessas novas portas que se abriram para explorar essas diferentes formas de olhar, este fato pode nos trazer experiências que numa etnografia mais clássica talvez não se apresente.

O olhar é socialmente e culturalmente construído e quando uma pesquisa pretende lidar com imagens cinematográficas isso também é levado em consideração, já que para produzir um filme estabelecem-se escolhas vindas de pessoas reais, que vão desde o roteirista até os atores que interpretam os personagens.

Quando um pesquisador pretende realizar um trabalho de campo logo vêm à tona indagações sobre o tema escolhido. Com isso, o interesse em tentar resolver o problema estipulado origina-se da pergunta que foi formulada. Nesse sentido, ao refletir sobre a relação cinema e imaginário social, perceber que representações imagéticas da velhice são demonstradas simbolicamente na produção cinematográfica, que podem nos levar a refletir numa questão mais ampla, entre cinema e sociedade, torna-se um grande desafio. Deste modo, os filmes contêm "representações de um imaginário social cotidianamente recriado e em movimento" (BARBOSA; CUNHA, 2006, p.55).

Compactuando com o tema dos filmes Copacabana e Chega de Saudade, a velhice torna-se, no cotidiano contemporâneo, um debate que 
ultrapassou esferas da vida social. Situando os filmes a um contexto ${ }^{4}$ estes que no caso são sobre a velhice, transmitem a possibilidade de perceber resquícios ou partes de nossa realidade, em que a cautela se faz necessária, pois os filmes estão inseridos num processo que reproduz significados possíveis ao mundo, servindo também como forma de dialogar com as normas que encontramos em nossas sociedades.

Nesse sentido, a forma com que nos apropriamos dele servirá como um instrumento enriquecedor para contribuições de indagações sobre o assunto que envolva terceira idade o cinema e suas imagens, estas que "podem ser pensadas como forma de ver, olhar e pensar ampliando as possibilidades de análise nos domínios do visível" (BARBOSA; CUNHA, 2006, p. 59).

Palavras Chave: Antropologia visual, Análise fílmica, Cinema, Velhice

\section{Referências}

ALVES, Andréa Moraes. A dama e o cavalheiro: um estudo antropológico sobre envelhecimento gênero e sociabilidade. Rio de Janeiro: FGV, 2004.

Os idosos, as redes de relações sociais e as relações familiares. In: NERI, Anita Liberalesso (org.). Idosos no Brasil: vivências, desafios e expectativas na terceira idade. Edições SESC. São Paulo: Fundação Perseu Abramo, 2007. 125-139.

BARBOSA, Andréa. São Paulo: Cidade Azul. Imagens da cidade construídas pelo cinema paulista dos anos 80. São Paulo: Tese de doutorado. Departamento de Antropologia/FFLCH/USP, 2003.

\footnotetext{
${ }^{4}$ Ver: VANOYE, Francis; GOLIOT-LETÉ, Anne. Ensaio Sobre a Análise Fílmica. $9^{\circ}$ edição. Tradução de Maria Appelenzeller. Revisão Técnica de Nuno César P. de Abreu. Campinas: Papirus, 2009.
} 
; CUNHA, Edgar Teodoro da. Antropologia e Imagem. Jorge Zahar.

Rio de Janeiro, 2006.

BARROS, Myriam Moraes Lins de. Densidade da memória, trajetória e projeto de vida. Dossiê gênero e velhice. Vários colaboradores. In: Revista estudos feministas. IFCS/UFRJ. Vol.5 N.1 ano 1997.

DEBERT, Guita Grin. A Reinvenção da velhice: Socialização e Processos de Reprivatização do Envelhecimento. Editora da Universidade de São Paulo. Fapesp. São Paulo, 2004.

A Vida Adulta e a Velhice no Cinema. In: GUSMÃO, Neusa Maria Mendes de (org.). Cinema velhice e cultura: cinedebate. Campinas/ São Paulo, Alínea, 2005.

DÖPPENSCHMITT, Elen. Velhice e Memória em Copacabana. In: GUSMÃO, Neusa Maria Mendes de (org.). Cinema velhice e cultura: cinedebate. Campinas/ São Paulo, Alínea, 2005.

GEERTZ, Clifford. Interpretação das culturas. Rio de Janeiro, Zahar, 1978.

GUSMÃO, Neusa Maria Mendes de. Velhice, Cinema e o Trânsito do tempo. In: GUSMÃO, Neusa Maria Mendes de (org.). Cinema, Velhice e cultura: cinedebate. Campinas/ São Paulo, Alínea, 2005.

LOPES, Andréa. Velhice, heterogeneidade e a dança dos esquisitos. In: GUSMÃO, Neusa Maria Mendes de; SIMSON, Olga Rodrigues de Moraes Von (orgs.). Velhice e diferenças na vida contemporânea. Campinas/São Paulo, Alínea, 2006.

LOPES, Ruth G. da Costa. Imagem e auto-imagem: da homogeneidade da velhice para a heterogeneidade das vivências. In: NERI, Anita Liberalesso (org.). Idosos no Brasil: vivências, desafios e expectativas na terceira idade. Editora Fundação Perseu Abramo, Edições SESC. São Paulo, 2007. pp.141-152.

NOVAES, Sylvia Caiuby. "Imagem e ciências sociais: Trajetória de uma relação difícil". In: BARBOSA, Andréa, CUNHA, Edgar Teodoro; HIKIJI, Rose Satiko Gitirana. Imagem 
- Conhecimento: antropologia, cinema e outros diálogos. São Paulo/ Campinas: Papirus, 2009.

PEIXOTO, Clarice E. Envelhecimento e Imagem: As fronteiras entre Paris e Rio de Janeiro. São Paulo: Annablume, 2000.

História de mais de 60 anos. Dossiê gênero e velhice. Vários colaboradores. In: Revista estudos feministas. IFCS/UFRJ. Vol.5 N.1 ano 1997.

SALLES, João Moreira. "A dificuldade do documentário". In: Martins, Eckert \& NOVAES, Sylvia Caiuby (orgs.) O imaginário e poético nas Ciências Sociais. Bauru: EDUSC, 2005. pp.57-72.

SANT'ANNA Denise Bernuzzi de. Entre os corpos e os incorporais. In: Vários colaboradores. Velhices: reflexões contemporâneas. São Paulo: SESC: PUC, 2006.

TAVARES, Samila Sathler. Identidade e Sociabilidade na Velhice em tempos de Transição. In: Cinema velhice e cultura: cinedebate. Campinas/ São Paulo, Alínea, 2005. VANOYE, Francis; GOLIOT-LETÉ, Anne. Ensaio Sobre a Análise Fílmica. $9^{\circ}$ edição. Tradução de Maria Appelenzeller. Revisão Técnica de Nuno César P. de Abreu. Campinas: Papirus, 2009.

FILMES:

Copacabana, direção Carla Camurati. Rio de Janeiro, Brasil, 2001, cor, 92 min.

Chega de Saudade, direção Laís Bodansky. São Paulo, Brasil, 2008, cor, 95 min. 